\title{
Failure of Height-adjustment Hydraulic System in a Dual-Drum Shearer and Surface Modifications on Key Parts
}

\author{
Wen Shu ${ }^{1}$ \\ School of Engineering and Technology \\ China University of Geosciences (Beijing) \\ Beijing 100083, China \\ email: saharashu@163.com \\ Xiang $\mathrm{Yu}^{2} *$ \\ School of Material Science and Technology \\ China University of Geosciences (Beijing) \\ Beijing 100083, China \\ email:yuxiang690625@aliyun.com
}

\author{
Lei Zhang ${ }^{3}$ \\ School of Engineering and Technology \\ China University of Geosciences (Beijing) \\ Beijing 100083, China \\ email: zhanglei2624@cugb.edu.cn
}

\begin{abstract}
In a dual-drum shearer, the drum's height is mainly adjusted by a height-adjustment hydraulic system. However, the hydraulic system is prone to failures, since oil is likely to leak induced by the abrasions of key parts. In the present work, based on the analysis of system failures and the requirements on material performances, the surface modification methods used for the key parts in heightadjustment hydraulic system were proposed. Specifically, the TiN film was deposited on the surface of the oil distribution disk, the diamond-like carbon (DLC) film was deposited on the surface of the cylinder by means of ion implantation and the ion cladding was performed on the surface of the plunger piston. Compared with the original base material, the material after processed is significantly enhanced in terms of surface performances. The results also indicate that, after modified, the parts' surface performances were greatly improved and now can satisfy the demands under harsh operating conditions. Accordingly, the failure rate of the hydraulic system can be reduced and the service period of the shearer can be prolonged.
\end{abstract}

Keywords- Coal mining machine; Higher institutions; Hydraulic system; Component failure; Surface modification

\section{INTRODUCTION}

A double-ended miner (double-drum shearer) is a preferred choice for coal mining in medium-thick seams. For a shearer, the control system is mainly used for controlling over two parameters - the traction speed and the drum's height. The adjustment of the drum's height refers to that, when the sheared is driven by a traction power, the drum's height will be adjusted within the seam's height range, so as to adapt to the variation of the working surface's thickness [1]. The traction and heightadjustment mechanisms are generally controlled and implemented by a hydraulic system. Consequently, whether the hydraulic system normally operates or not directly affects the operating condition of the shearer.

However, the hydraulic system is a failure-prone part. The failure of the hydraulic system is a chief culprit for the shearer' s malfunction, i.e., nearly $40 \%$ of the shearers' malfunctions are caused by the failures of hydraulic system [2]. The oil leakages induced by the abrasion of key parts are primarily responsible for the hydraulic system' s failures, which will flow into the parts and then cause pollutions and abrasions, finally leading to the malfunction of the whole system. To settle these problems, the following two methods are frequently used: (i) to optimize the parts and mechanism through machine design, and (ii) to optimize the materials' performances by means of thermal treatment. Using the former method, the abrasions under harsh operating conditions cannot be eliminated. On the other hand, by thermal treatment, the tolerance requirements of the parts cannot be satisfied, and the parts' performance requirements under harsh operating conditions cannot be achieved.

Surface modification is an advanced technique to improve the parts' functional performances by varying their surface composition and structure, mainly using chemical and physical vapor deposition methods. By preparing the micrometer-scale hard coatings on the surface of metal parts, not only the tolerance requirements can be satisfied, but also the required modified coatings can be synthesized in line with the parts' utilization requirements [3]. Without any changes on the system structure and hydraulic circuit of the existing system, we can perform surface modifications on the key parts, contributing to the reduction of the system' $\mathrm{s}$ failure rate and the prolonging of the shearer' $s$ service life. So far there is no report regarding the modification on the hydraulic parts in a shearer. Therefore, based on the analyses of system failures, the present work proposed some surface modification methods on the key heightadjustment hydraulic parts [4]. 
(a)

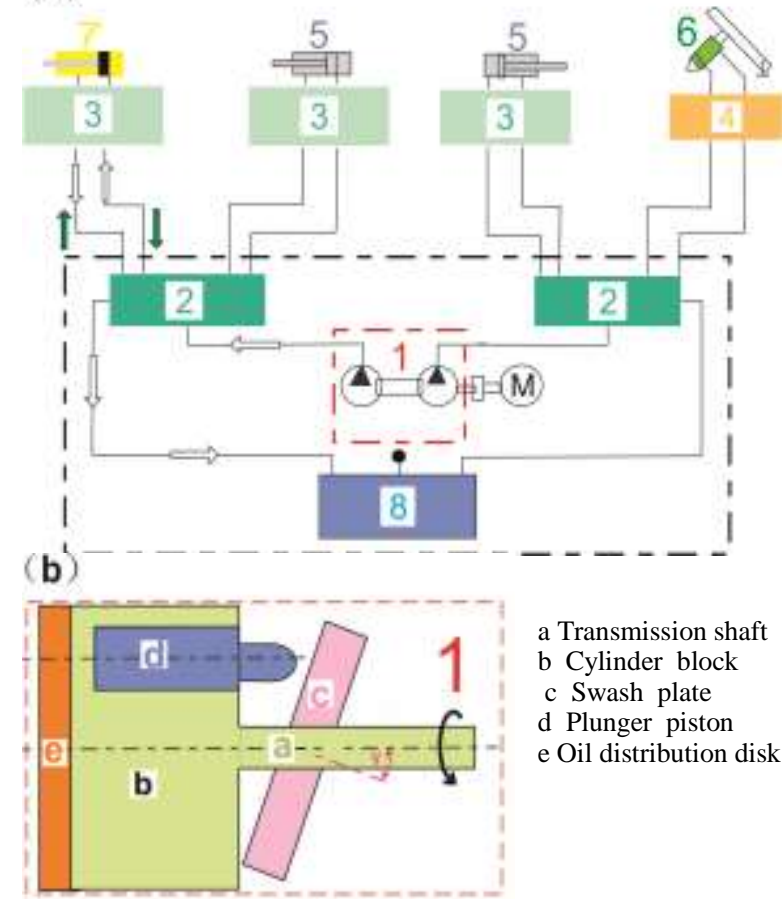

Figure 1. (a) Working principle of the height-adjustment hydraulic system in a shearer; (b) Working principle of the main oil pump.

1.Main oil pump 2. Bi-directional control valve 3.Decreasing blocking valve 4.Bi-directional blocking valve 5.Height-adjustment cylinder 6.Right height-adjustment cylinder 7. Left height-adjustment cylinder 8 . Oil tank

\section{FAILURES OF THE HYDRAULIC SYSTEM IN HEIGHT- ADJUSTMENT MECHANISM AND THE RELATED COUNTERMEASURES}

\section{A. Working principle of the hydraulic system and failure analysis}

Fig .1 illustrates the working principle of the heightadjustment hydraulic system, in which the structure of the main oil pump is displayed in the embedding graph. When the hydraulic system operates, the electromotor drives the cylinder block (b) to rotate through the transmission shaft (a) in main oil pump (1). Under the action of the swash plate (c), the plunger is forced to make reciprocating motion inside the cylinder, and then the oils are absorbed and pressed through the oil distribution window in the oil distribution disk [5].

The hydraulic oil is pumped to bi-directional control valve (2) by main oil pump. The bi-directional control valve is designed for controlling the motion direction and resetting of the piston rod in the cylinder, and the cylinders (5, 6 and 7) are used for controlling the working height and direction of the drum. Taking the right height-adjustment cylinder (7) as the example, the hydraulic oil passes through the bi-directional control valve and flows into the rodless cavity on the right side of the cylinder according to the directions indicated by the white arrows [6]. Accordingly, the piston rod is driven to move toward the left side. After finishing the work, the inlet direction of the hydraulic oils is changed by the bi-directional control valve, and the hydraulic oil flows into the rod cavity on the left side of the cylinder according to the directions indicated by the green arrows. Then the piston rod is driven to move toward the right side, and the resetting of the piston is finished. After reset, the hydraulic oil flows into the oil tank (8) through the bi-directional control valve (2). The blocking valves should be placed in all cylinder circuits. With the use of the blocking valves 3 and 4 , the oil circuits can be opened or closed to make the piston rod in the oil cylinder stay at the required positions.

When the main oil pump normally runs, the rated operating pressure can reach up to $32 \mathrm{GPa}$ and the rated rotating speed exceeds $1500 \mathrm{r} / \mathrm{min}$, with a theoretical flow of $34.51 / \mathrm{min}$. All the parts bear great pressure. Especially, the heat is easily generated during the high-speed movements of the oil distribution disk, cylinder and plunger piston, giving rise to the leakages of hydraulic oil. These oil particles then rub against some parts, producing pollutions and abrasions of the parts [7].Finally, the whole system will be out of order. As a consequence, people now turn attention to exploring the methods to improve the abrasive resistance performances of the key parts of the hydraulic system in height-adjustment mechanism.

\section{B. Solutions to the failures of hydraulic system}

In terms of improving leakproof and abrasive resistance performances of the key parts of the heightadjustment hydraulic system in a shearer, the following two methods are commonly used. One is to optimize the parts' structure through mechanical design; however, the failures during operating period cannot be eliminated. The other method is to improve the parts' material properties by means of thermal treatment; unfortunately, the required mechanical properties for abrasion resistance sometimes cannot be satisfied. We found that, by performing surface strengthening treatment on the key hydraulic parts, the abrasions and pollutions caused by oil leakages during the operation process can be eliminated [8]. Moreover, without any changes on the existing system structure and hydraulic circuit, surface modifications on key parts are expected to reduce the failure rate of the hydraulic system and prolong

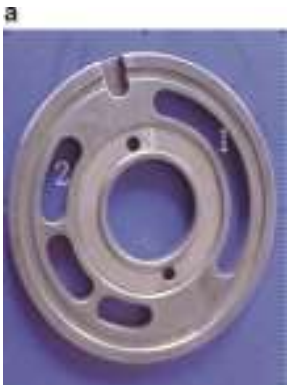

Figure 2. (a) Picture of an oi distribution disk; (b) Abrasive mechanisms of the oil distribution disk; (c) the terminal point of oil discharge in the plunger piston.

1. Oil inlet; 2 . Oil distribution outlet; 3 Terminal point of oil discharge

b

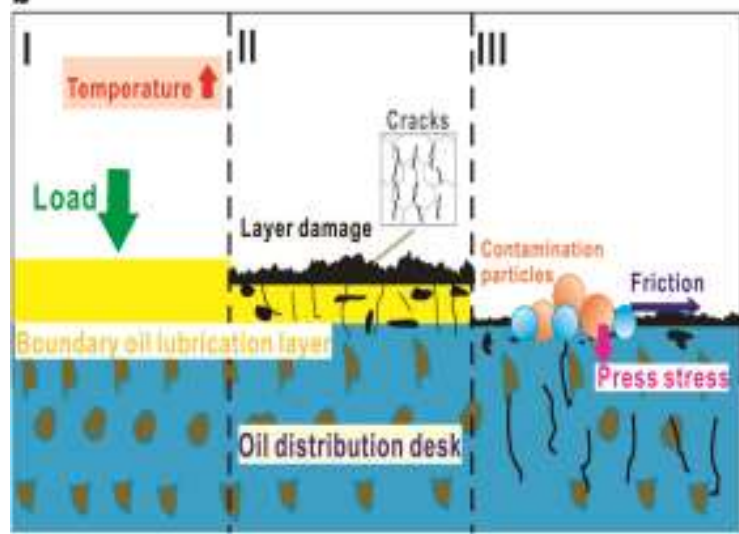


the service life of the shearer.

\section{FAILURE ANALYSIS AND SURFACE MEDICATIONS ON THE KEY PARTS}

\section{A. Oil distribution disk of the main oil pump}

In the main oil pump, the oil distribution disk is mainly used for controlling the flowing in and out of the oils. As show in Fig .2a, Hole 1 denotes an oil inlet, Hole 2 denotes an oil discharge outlet and Hole 3 denotes the terminal point of oil discharge in the plunger piston. As described above, Fig .1 illustrates the structure of the main oil pump, from which we can observe that, when the rotating angle of the cylinder ranges from $180^{\circ}$ to $360^{\circ}$, the plunger piston is extended toward the outside and the sealed working volume at the bottom of the plunger piston increases, leading to the absorption of oils through the oil inlet (Hole 1) in the oil distribution disk; when the rotating angle ranges from $0^{\circ}$ to $180^{\circ}$, the plunger piston is pushed into the cylinder by the swash plate, and the sealed volume declines, leading to the pressure of oils through the oil outlet (Hole 2) in the oil distribution disk.

The failure mechanisms of the oil distribution disk are displayed in Fig .2b. The failures of the oil distribution disk result from the abrasive wears under oil lubrication conditions, and the abrasive particles come from the solid particles in oil pollutions. In the Stage I, during the working period, the cylinder rotates at a high speed and the temperature rises, which is prone to causing oil leakages. In the Stage II, the oil is sucked through the frequent impacts between the plunger piston and the oil distribution disk, producing a reciprocating impact force. Due to the effects of this impact force and temperature rising, the boundary lubricating films on the contact surface between oil distribution disk and hydraulic oil is easy to be destroyed [9]. The direct fiction between solid abrasive particles and oil distribution disk inevitably initiate the generation of microcracks. In the Stage III, the polluted particles flow into the oil-distributing pair together with the spilled oils. Under the action of the reciporating impact force, the abrasive particles produced rolling force on the surface, and the surface cracks grow, leading to the abrasive failure of oil distribution disk, the aggravated oil leakages in oil-distributing pair and the reduced volume in main pump. Finally, the main pump cannot operate normally.

The oil distribution disk is made of ball bearing steels, which is processed by quenching treatment combined with low-temperature tempering. In order to meet the requirements on abrasive resistance performance, the surface is reinforced by some chemico-thermal treatments such as nitriding method. Currently, the nitrided oil distribution disks are commonly used in coal mining industry. Taking the GCrl5 oil distribution disk as the example, the micro-hardness of the base material is approximately $5 \mathrm{GPa}$ and the hardness of the nitrided layer is up to 9-10 GPa. However, it cannot satisfy the performance requirements on the material's surface under some harsh operating conditions. A super-hard TiN film with the thickness of $3 \mu \mathrm{m}$ was synthesized on the base material by means of vacuum multi-arc ion plating technique. The harness of this film can reach up to $45 \mathrm{GPa}$. Moreover, this film is uniform and compact, and also exhibit strong binding force [10]. Consequently, the nitriding treatment is quite suitable for the surface modification on oil distribution disk under harsh operating conditions.

\section{B. Cylinder block}

Hydraulic cylinder is the load-bearing component for hydraulic oil. During coal mining process, the cylinder sustains the continuous loading for a long time, and the pollution particles in oil after leakage directly strike and corrode the cylinder's working surface which is adjacent to the oil distribution disk. As a consequence, the bubbles and hole corrosions appear on the cylinder's surface. More seriously, the cylinder even may fail to work because of abrasive failures. It means that, in addition to high strength, the hydraulic cylinder should have sufficient abrasive resistance and erosion resistance performances, so as to prevent the abrasions caused by the impact of oil particles on the surface. For the parts whose surfaces were processed using the traditional thermal treatment methods such as rolling quenching method, the problems of stress concentration and fatigue failure cannot be avoided.

In our opinion, the cylinder's surface should be modified with the use of ion implantation method. Fig .3 illustrates the working principle of plasma immersion ion implantation (PIII) technique, in which 1 denotes the power supply, 2 denotes the injected gases, 3 denotes the ionized gas particles and 4 denotes the part. After powered on, the plasma is produced, in which the injected gases are ionized. Under the action of high voltage, the ionized gas particles are injected to the surface of base materials. After ion implantation, the surface and subsurface structures of the materials varied, and therefore, the surface performance can be improved.

In the present work, the diamond-like carbon (DLC) film was synthesized on the surface of steel base by means of ion implantation [11]. This DLC film exhibit several advantages such as high hardness and low friction. The comparison results of erosion resistance performances between the steel base coated by DLC film and the uncoated steel base are presented in Fig .4. In the erosion resistance performance tests, the sand grains were applied to hit against the material surface, and then the data of the erosion scars (including depth and width) were then measured and recorded. It can be easily found that, after coated by DLC film, both the width and depth of the erosion scar on the surface of the steel base are reduced significantly, specifically, the width and depth are reduced by 4 and 6 times compared with the data of the uncoated steel base.

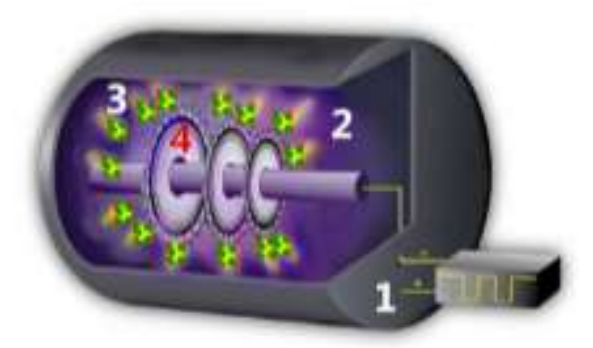

Figure 3. Working principle of ion implantation.1. Power supply; 2 Injected gases; 3. Ionized and excited particles; 4. Substrate 

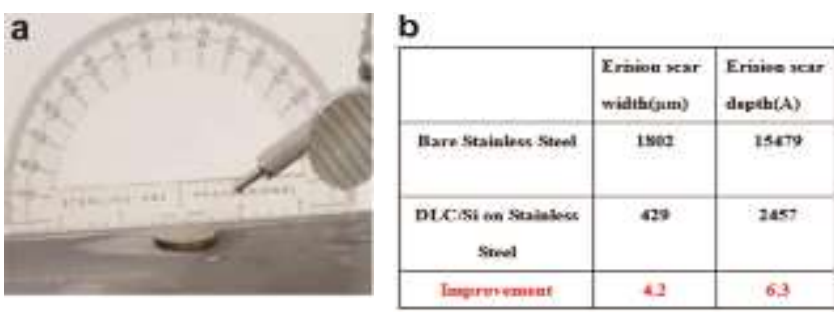

Figure 4. Comparison results of erosion resistance performances between the steel base coated by DLC film and the uncoated steel base.

(a) Erosion resistance performance tests; (b) Comparison results of the erosion scars.

\section{Plunger piston}

The abrasive mechanisms of the plunger piston are illustrated in Fig .5a. The oil-absorption and oil-discharge processes in the main oil pump are completed by the reciprocating movements of the plunger piston. The plunge piston and cylinder constitute a friction pair. As shown in Fig .5b, the gases mixed in the oils can become the bubbles under pressure, and the high-pressure oil is pressed into the plunger hole by the plunger piston. In the press-into regions between plunger piston and cylinder, the bubbles are pressed and become many minute bubbles. Some minute bubbles adhere to the outside surface of the plunger piston, and break down due to the effects of high pressure and temperature rising. After burst, the gases are sprayed to the outside surface of the plunger piston and thus the cavitation erosions are generated. As shown in Fig .5c, since the cavitation corrosions frequently appear on the surface of plunger piston, some pits and hole corrosions appear. Finally, the plunger piston is broken, and the oil pressure operation cannot be implemented. Conclusively, the surface material of plunger piston should have favorable abrasive resistance and erosion resistance performances, so as to prevent from the appearance of bubbles.

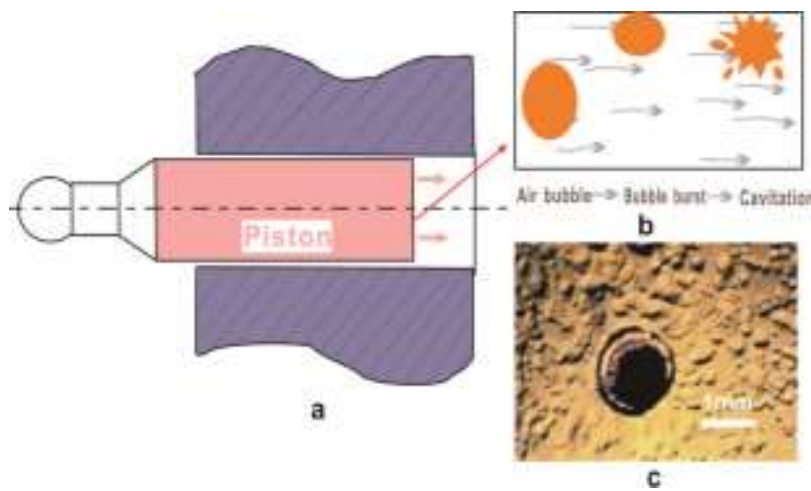

Figure 5. Working principle of the plunger piston and the formation of cavitation corrosion on the surface.

(a) Working principle of the plunger piston; (b)The formation of cavitation; (c) Formation of cavitation corrosion.

We believe that the outside surface of the plunger piston can be modified using laser cladding, and the working principle is illustrated is elaborated in Fig .6. The cladding materials are firstly selected and placed on the surface of the precoated parts. Under laser irradiation, the cladding materials and the base surface are melted simultaneously [12]. After rapid solidification, the melted materials metallurgically bond with the base material to produce the surface coating. Accordingly, the abrasive resistance and erosion resistance performances of the part' s surface can be improved. Compared with the coatings by traditional thermal treatment methods, laser cladding layers exhibit the following characteristics: controllable thickness, strong bonding with the base material, uniform and compact texture and fairly small thermal deformations on the base materials; i.e., the problems of cavitation corrosion can be effectively settled. For example, the laser cladding is performed on the plunger piston made up of nodular cast ions. The copperbased alloy powders are selected as the cladding materials, in which $\mathrm{Si}$ and $\mathrm{B}$ were added in order to prevent oxidization. We can observe that the high-strength copper alloy coated on the surface of plunger piston can satisfy the requirements in surface modification.
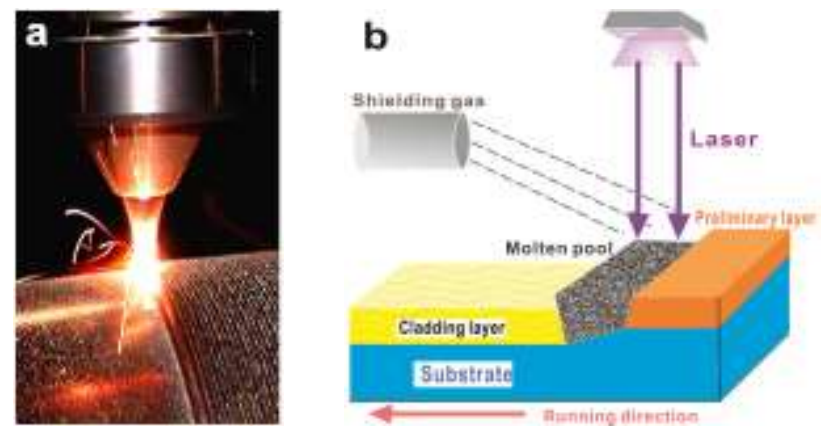

Figure 6. Working principle of laser cladding.

(a) Picture of cladding operation; (b) Working principle.

\section{CONCLUSION}

In practical applications, the hydraulic system in the shearer' s height-adjustment mechanism is prone to failures mainly due to oil leakages. Our work analyzed the working principle of the height-adjustment hydraulic system in a shearer and selected three key parts in which the failures frequently occur. Based on the analyses on their abrasion mechanisms and the requirements on material performances, the relevant methods for strengthening surface modifications were proposed. Specifically, the TiN film was deposited on the surface of oil distribution disk, the diamond like carbon (DLC) film was deposited on the surface of cylinder by means of ion implantation and the ion cladding was performed on the surface of plunger piston. After processed, the parts' surface performances are significantly improved. Accordingly, we have reasons to believe that, by performing surface strengthening on the key parts, the surface performances can be effectively improved and thus the hydraulic system' $\mathrm{s}$ failures can be significantly reduced, leading to the prolonging of the shearer' $\mathrm{s}$ service life.

\section{ACKNOWLEDGEMENT}

This work was supported by the Fundamental Research Funds for the Central Universities. 


\section{REFERENCES}

[1] X. P. Su, W. Li, and Q. G. Fan, "A shearer drum height adjusting strategy using sliding-mode variable structure control," Journal of the China Coal Society / Mei Tan Xue Bao, Dec. 2012, Vol. 37, pp. 2107-2111.

[2] J. Sheaf and J. Robert, "Hydraulic system causes structural failure," Hydraulic Pneum., Vol.67, 2014, pp.72.

[3] M. Singh, G. S. Lathkar, and S. K. Basu, "Failure Prevention of Hydraulic System Based on Oil Contamination," Journal of The Institution of Engineers (India): Series C. India, Vol.93, 2012, pp. 269-274.

[4] M. N. Feng, X. Huang, H. L. Tang, and X. B. Liu, "Effects of surface modification on interfacial and rheological properties of CCTO/PEN composite films," Colloids and Surfaces A: Physicochemical and Engineering Aspects, Vol.441, 2014, pp.311316.

[5] L. K. Malik, "A System for Monitoring of the State of Damming Hydraulic Structures,” Water Resour., Vol.30, 2012, pp.689-695.

[6] R. Doddannavar and A. Barnard, Practical hydraulic systems, Elsevier :Newnes , CA: University Science, 2005.
[7] A. Izadian, S. Hamzehlouia, M. Deldar, and S. Anwar, "A Hydraulic Wind Power Transfer System: Operation and Modeling," Ieee T Sustain Energ., Vol.5, 2014, pp.457-465.

[8] L. F. Quilumba, K. L. Lee, W. J. Lee, and A. AHarding, "Improving Hydraulic System Energy Efficiency With HighPerformance Hydraulic Fluids," Ieee T Ind Appl., Vol.50, 2014 pp.1313-1321.

[9] D. Catic, M. Gasic, M. Savkovic, and J. GlisovicI, "Fault tree analysis of hydraulic power-steering system," Int J Vehicle Des, Vol.64, 2014, pp.26-45 .

[10] X. Yu, C. B. Wang, M. Hua, P. Tam, Y. Liu, and D. Yu,“Adherent nano-superhard titanium nitride film and its forming mechanism in multi-arc ion-plating system," Surf Rev Lett., Vol.14, 2007, pp.789-793.

[11] R. H. Wei, "Development of new technologies and practical applications of plasma immersion ion deposition (PIID)," Surf Coat Tech., Vol.204, 2010, pp.2869-2874 .

[12] W. J. Wang, J. Hu, J. Guo, Q. Y. Liu, and M.H. Zhu, "Effect of laser cladding on wear and damage behaviors of heavy-haul wheel/rail materials," Wear., Vol.311, 2014, pp.130-136. 